This is the author's final, peer-reviewed manuscript as accepted for publication. The publisher-formatted version may be available through the publisher's web site or your institution's library.

\title{
A qualitative analysis of military couples with high and low trauma symptoms and relationship distress levels
}

Stephanie Wick, Briana S. Nelson Goff

\section{How to cite this manuscript}

If you make reference to this version of the manuscript, use the following information:

Wick, S., \& Nelson Goff, B. S. (2014). A qualitative analysis of military couples with high and low trauma symptoms and relationship distress levels. Retrieved from http://krex.ksu.edu

\section{Published Version Information}

Citation: Wick, S., \& Nelson Goff, B. S. (2014). A qualitative analysis of military couples with high and low trauma symptoms and relationship distress levels. Journal of Couple \& Relationship Therapy: Innovations in Clinical and Educational Interventions, 13(1), 6388.

Copyright: Copyright @ 2014 Taylor \& Francis Group, LLC

Digital Object Identifier (DOI): doi:10.1080/15332691.2014.865983

Publisher's Link:

http://www.tandfonline.com/doi/full/10.1080/15332691.2014.865983\#.VBilY8VdW_E

This item was retrieved from the K-State Research Exchange (K-REx), the institutional repository of Kansas State University. K-REx is available at http://krex.ksu.edu 
Running head: WAR-RELATED TRAUMA AND COUPLES

\title{
A Qualitative Analysis of Military Couples with High and Low Trauma Symptoms and Relationship Distress Levels
}

\author{
Stephanie Wick \\ Briana S. Nelson Goff \\ Kansas State University
}

Stephanie L. Wick, PhD, Army Substance Abuse Program (ASAP), Building 7424, Apennines Drive, Fort Riley, KS 66442; stephaniewick123@hotmail.com.

Briana S. Nelson Goff, PhD (Corresponding Author) is Professor, School of Family Studies and Human Services, Kansas State University, 343K Justin Hall, Manhattan, KS 66506-1401; Phone 785-532-1490; Fax 785-532-5505; bnelson@ksu.edu.

Support for this research was provided by funding from a Kansas State University Small Research Grant and the Kansas State University College of Human Ecology SRO Grant. 


\begin{abstract}
The purpose of the current study was to understand the experiences of a subset of military couples regarding the effects of war deployment on couple functioning. This study utilized the core “couple functioning” variables included in the Couple Adaptation to Traumatic Stress Model (Nelson Goff \& Smith, 2005) as sensitizing concepts to guide the qualitative analysis process. Participant interviews ( $n=15$ couples, 30 total participants) were divided into subgroups according to high and low trauma symptom and relationship satisfaction scale scores. Five primary themes were identified in the results: communication, conflict management, roles, support/nurturance, and post-traumatic growth. Overall, highly satisfied couples and those with the lowest levels of traumatic stress symptoms reported more positive relationship functioning in the identified areas, while couples reporting higher traumatic stress symptoms and lower relationship satisfaction indicated varied or inconsistent qualitative results. Clinical and research implications for military couples also are identified.
\end{abstract}


A Qualitative Analysis of Military Couples with

High and Low Trauma Symptoms and Relationship Distress Levels

\section{Traumatic Stress and Related Symptoms in Soldiers}

Estimates indicate that nearly 30\% of Vietnam veterans, 10\% of Gulf War (Desert Storm) veterans, 6 to 11\% of Afghanistan War (Operation Enduring Freedom, OEF) veterans, and 12 to $20 \%$ of veterans of the Iraq War (Operation Iraqi Freedom, OIF) have developed posttraumatic stress disorder (PTSD) as a result of their time on the battlefield (National Center for PTSD [NCPTSD], 2009). Deployments to Operations Enduring Freedom, Iraqi Freedom, and New Dawn have been longer, reoccurring deployments to combat is common, and breaks between deployments have been infrequent (Tanielian \& Jaycox, 2008). Earlier efforts to understand combat-related trauma and PTSD focused primarily on its impact on the soldier. More recent studies have begun to recognize the systemic impact of trauma and PTSD on the veteran's spouse and family system.

\section{Secondary Traumatic Stressors for Partners}

Perhaps most relevant to war-related trauma is the prevalence of secondary traumatic stress (Figley, 1985). The theory of secondary traumatic stress contends that being in close contact with and emotionally connected to a traumatized person becomes a chronic stressor, and family members often experience symptoms of traumatization (Arzi, Solomon, \& Dekel, 2000; Dekel \& Monson, 2010; Nelson Goff \& Smith, 2005). In other words, although trauma can have a direct impact on the trauma survivor through the manifestation of his or her spouse's/partner's trauma symptoms, the couple may also experience individual and interpersonal problems including marital disruption, sexual dysfunction, communication problems, and problems with intimacy (Monson, Taft, \& Fredman, 2009; Nelson Goff, Crow, Reisbig, \& Hamilton, 2007, 2009; Nelson \& Wampler, 2000; Renshaw, Rodrigues, \& Jones, 2008, 2009). 
Previous empirical work by Solomon and colleagues (Arzi et al., 2000; Mikulincer, Florian, \& Solomon, 1995; Solomon, Waysman, Belkin, Levy, Mikulincer, \& Enoch, 1992; Solomon, Waysman, Levy, et al., 1992) has focused on the effects of combat trauma on the spouses/partners of veterans. These authors found combat stress reaction (CSR) and PTSD in husbands to be related to greater somatization, depression, anxiety, loneliness, hostility, and impaired marital, family, and social relations in wives. Dirkzwager, Bramsen, Adèr, and van der Ploeg (2005) reported increased PTSD symptoms, somatic problems, sleep disorders, more negative social support, and more marital/relationship problems in partners of Dutch military peacekeepers with PTSD than the partners of non-PTSD peacekeepers. While clinical and empirical trauma literature has emphasized the survivor's symptoms, the systemic effects of trauma on couple and family relationships have received attention only recently.

\section{Interpersonal Impact of Trauma}

Trauma, specifically combat or other military-related traumatic experiences, may be particularly detrimental couple and family functioning (Dekel \& Monson, 2010; Dirkzwager et al., 2005; Ruger, Wilson, \& Waddoups, 2002). Research by Riggs, Byrne, Weathers, and Litz (1998) indicated that over $70 \%$ of the PTSD veterans and their partners reported clinically significant levels of relationship distress, compared to $30 \%$ of the non-PTSD couples. The degree of relationship distress was related to the severity of veterans’ PTSD symptoms, specifically symptoms of avoidance and emotional numbing. Cook, Riggs, Thompson, Coyne, and Sheikh (2004) found similar results, with emotional numbing or avoidance being the most significant predictor of lower relationship satisfaction in a sample of World War II repatriated prisoners of war. Other reports suggested that Vietnam veterans with PTSD are twice as likely as their non-PTSD counterparts to have been divorced and almost three times as likely to have experienced multiple divorces (Kulka et al., 1990). Riggs and colleagues (1998) found that veterans with PTSD and their partners had taken 
more steps toward separation than the non-PTSD couples in their study. While the impact of trauma exposure and PTSD may negatively impact soldiers and spouses, recent research by Karney and Crown (2007) has found no support for the reports of OIF/OEF/OND war deployment contributing to higher divorce rates among military families. While it is clear from the research that military service is stressful for families (Karney \& Crown, 2007), how that deployment-related stress impacts military couples needs to be further explored.

Recent research on the impact of military deployments to Iraq and Afghanistan since 2003 has found additional support for the negative impact of soldiers' symptoms on spouses' individual symptoms and marital satisfaction (Allen, Rhoades, Stanley, \& Markman, 2010; Hamilton, Nelson Goff, Crow, \& Reisbig, 2009; Nelson Goff et al., 2007, 2009; Renshaw et al., 2008, 2009). In a smaller qualitative study, which was not specifically a military sample, Nelson Goff and colleagues (2006) used interviews from nine clinical couples in which at least one couple had experienced a traumatic event. Their findings suggested that interpersonal relationships of trauma survivors may have characteristics that are uniquely trauma- based. For example, communication was found to play a significant role in increased relationship functioning. Conflict avoidance patterns may also be due to trauma survivors' symptoms of arousal, which can be extremely detrimental to interpersonal functioning. Other salient themes identified in the 2006 study included those associated with levels of cohesion/connection, support, understanding, sexual intimacy and relationship distress. This prior research on trauma in couples has been developed into the Couple Adaptation to Traumatic Stress (CATS) theoretical Model (Nelson Goff \& Smith, 2005), which will be described next.

\section{The Couple Adaptation to Traumatic Stress (CATS) Model}

A current model of systemic traumatic stress in the literature is the Couple Adaptation to Traumatic Stress (CATS) Model (Nelson Goff \& Smith, 2005). This empirically-based model includes the primary and secondary trauma effects on individuals, as well as interpersonal effects 
within couple systems. “The CATS Model provides a systemic description of how individual and couple systems are affected when trauma has occurred... however... adaptation to traumatic stress in the couple dyad is dependent on the systemic interaction of the three primary concepts: individual level of functioning, predisposing factors and resources, and couple functioning” (Nelson Goff \& Smith, 2005, p. 151).

Taken together, the individual levels of functioning and any predisposing factors and personal resources directly affect the quality of relational functioning within the couple system. The "couple functioning” component in the CATS Model is based on specific areas identified in the clinical and empirical literature, including issues relevant to attachment, relationship satisfaction, support/nurturance, power, role disruption, stability, adaptability, intimacy, communication, and conflict, which the authors have indicated as mutually influential components of the couple system. However, further evaluation is needed to validate the existence of the "couple functioning" components of the CATS Model.

\section{Purpose of the Current Study}

The recent conflicts in Iraq (Operation Iraqi Freedom/Operation New Dawn [OIF/OND]) and Afghanistan (Operation Enduring Freedom [OEF]) have necessitated frequent, long-term deployments of service members. This has left thousands of families to cope with the absence of their loved one, only to be re-united with a person who has likely undergone immense personal change as a result of war-related trauma. The resulting strain imposed on couples and families by the primary trauma survivor frequently encourages the development of secondary trauma symptoms in family members. The circular and mutually influential nature of trauma, coupled with the high numbers of returning OIF/OEF/OND veterans with PTSD, has created a situation in which countless couples may experience stress as a result of the complications created by exposure to war trauma (Di Nola, 2008; Eaton et al., 2008; Nelson Goff et al., 2007; Renshaw et al., 2008). 
The purpose of the current study was to understand the experiences of couples regarding the effects of war-related deployment trauma on couple functioning. The Couple Adaptation to Traumatic Stress (CATS) Model (Nelson Goff \& Smith, 2005) offers a constructive step toward a systemic understanding of trauma in dyadic systems. The current study specifically addressed the couple functioning variables included in the CATS Model (described previously) in subgroupings of OIF/OEF soldiers and their spouses. Data analyses were conducted across subgroups of couples that were identified based on high and low reported levels of traumatic stress symptoms and relationship satisfaction to determine which of these variables were reported as salient in these couple groups.

\section{Method}

\section{Research Procedures}

This study was part of a larger mixed-method study of trauma in military couples completed by the Trauma Research, Education, and Consultation at Kansas State University (TRECK) Team that utilized a research team of three doctoral students and a faculty member to conduct a series of interviews with military couples. The original study included results from 45 couples in two small cities in the Midwest that are close to Army posts near Kansas State University. At the time of the initial TRECK research study, Fort Riley KS had approximately 10,000 active-duty military personnel and 12,020 family members, and Fort Leavenworth KS had a population of approximately 5,253 military personnel and 4,613 family members ("Where are the Legions?”, 2005). Each of these original interviews was audiotaped and reviewed by the original research team. The research team included a faculty research advisor and doctoral students (under the supervision of the faculty advisor) conducting the research interviews, and undergraduate and graduate student assistants transcribing the interviews. 
The original study focused on three separate primary research questions that related to primary and secondary trauma symptoms in both partners, mechanisms by which systemic functioning may be affected by trauma, and the effects of trauma on interpersonal functioning. For the current study, secondary data analysis was utilized to address one primary research question, "In what way(s) is relationship functioning affected when couples report different levels of trauma symptoms (high vs. low) and relationships satisfaction (high vs. low)?” Specifically, this study utilized the following core terms included in the CATS Model as sensitizing concepts to guide the analysis process: attachment, satisfaction, stability, adaptability, support/nurturance, power, intimacy, communication, conflict, and roles (Nelson Goff \& Smith, 2005).

Interviews were conducted with each partner separately, audiotaped and transcribed verbatim for accuracy by a team of undergraduate research assistants. All interview transcripts were proofed and cross checked twice for accuracy, with the final interviews resulting in verbatim transcripts of each individual interview that were used for data analysis. Interviews ranged from approximately 30-90 minutes in length. For the current study, data from all 45 soldiers and 45 female partners were included in the initial analysis. Of the 24 questions included in the original qualitative interviews, the current study focused on the participants' responses to the questions pertaining to couple relational and interpersonal functioning, such as: How would you rate your partner's ability to listen when you talk about your deployment (or other events that happened in your past); How did your partner support you in your deployment or other trauma experience, When has your partner's deployment (or other trauma) had the most negative effect on your relationship; Have there been any positive effects from (the deployment/other trauma on your relationship" (The corresponding author may be contacted for a full description of the interview protocol.)

\section{Research Participants}


Various methods were used to recruit participants from the local communities, including publicly posted flyers and newspaper announcements; referrals from Army Family Readiness Groups, chaplains, and other local military sources; and referrals by other research participants. All recruitment occurred through contacts in the surrounding communities or through contacts directly to the researchers; no participants were recruited by the researchers contacting staff or soldiers directly through the military posts.

The sampling method of the original study was both purposive and convenience. This type of sampling technique was selected to ensure that cases were rich in information, depth, and detail. The intent was not to extrapolate the findings to the general population; rather, it was to elucidate on the impact of trauma on a very specific population (i.e., war deployed couples). Couples who met the outlined inclusion criteria volunteered to participate. These inclusion criteria included recent deployment to OIF or OEF, a minimum age of 18 years, involvement in their current relationship for at least one year, and no substance abuse or domestic violence at the time the initial telephone screening was made. Participating couples who completed questionnaires and the interview were compensated $\$ 50$.

The research procedure was approved by the Kansas State University Institutional Review Board (IRB), with assurances made to follow informed-consent procedures and to protect participant privacy and confidentiality. Military IRB approval was not included in the research procedure because the research project was not completed within the military system, nor were data collected on the military posts.

The total sample in the original study included 45 male soldiers and 45 female partners. Although female soldiers were not excluded from the sample, no female soldiers elected to participate. From the total sample, 15 couples ( $n=30$ participants) were selected to comprise the subsample, which was the primary sample utilized throughout data analysis in the current study. 
Among these participants, the average age for male soldiers was 30.3 years and 28.4 years for female partners (Range $=22-41 ; S D=5.11)$. For the male partners, 73\% were White $(n=11)$, $20 \%$ were African-American $(n=3)$, and 7\% were Mexican-American $(n=1)$. For the female partners, $80 \%$ were White $(n=12), 13 \%$ were American Indian/Alaska Native $(n=2)$, and $7 \%$ were African-American $(n=1)$. Among the female partners, 40\% reported some college, 27\% $(n=4)$ reported having a Masters degree, 20\% $(n=3)$ reported having completed college, and 13\% $(n=2)$ completed high school. For the male partners, 60\% $(n=9)$ had completed some college, $20 \%(n=$ 3) had completed college, 13\% $(n=2)$ had completed some graduate school, and 13\% $(n=2)$ had completed high school.

Nearly all of the male participants reported being employed full-time $(93 \%, n=14)$, and one participant reported being unemployed (not due to a disability). The income levels reported by the participants ranged from $\$ 10,000$ to $\$ 79,999$ annually, with the median income falling between $\$ 40,000$ and $\$ 49,999$. Female participants reported a full-time employment rate of 33\% $(n=5), 33 \%(n=5)$ were full-time homemakers, and 13\% $(n=2)$ were employed part-time. All participants in the subsample were married at the time of data collection. The average relationship length was 5 years, with a range of .5 to 12 years $(S D=3.84)$.

All but one male soldier had been deployed to Iraq (OIF); only one female partner reported a previous deployment (i.e., to Korea, prior to 9/11, and was not affiliated with the current OIF/OEF/OND conflicts). The average length of deployment for the male participants was 10.73 months (Range $=.5-13.5$ months; $S D=3.19$ ). Although participants' rank was inadvertently omitted from the data collection instrument, the 15 participants included a variety of ranks (based on income range) and jobs, including medics, pilots, platoon leaders, company commanders, records managers, and infantry members.

\section{Data Analysis}


Phase 1. Of the 34 questions included in the original qualitative interviews, the current study focused on the participants' responses to the 13 questions pertaining to couple relational and interpersonal functioning. The full data set from the original study was comprised of 90 interviews, which were reviewed in their entirety two times during the initial phase of the data coding and analysis process for the current study. Although all of the interviews were collected from individual partners, the analysis examined responses from couples. The first of the reviews was to acquire a general sense of the content of the interviews and potential themes and to initiate a process of convergence. By recognizing patterns revealed through recurring regularities within the data, a preliminary "sorting” of patterns into categories was possible.

Using the CATS Model (Nelson Goff \& Smith, 2005) as an existing theoretical framework, items categorized under the “couple functioning” component were explored. These items include deduced hypotheses from previous literature and theory identified by Nelson Goff and Smith (2005). Through a process of inductive analysis, new themes were identified. Indigenous concepts (i.e., key phrases, terms, and practices that are "special” to the participants) identified by the study participants (Patton, 2002) were inventoried and defined. In an effort to creatively synthesize and present the findings (Patton, 2002), a preliminary codebook of themes based on the CATS Model was established. This codebook utilized terms within the “couple functioning” portion of the CATS Model as sensitizing concepts (e.g., attachment, satisfaction, stability, support/nurturance, adaptability, power, intimacy, communication, conflict, roles).

In the current study, a single coder/analyst was used and interviews were reviewed multiple times to ensure a thorough investigation of themes. Data triangulation (methods triangulation) was achieved by using both quantitative measure scores and qualitative interview data sources, as well as theory-based constructs from the CATS Model (Nelson Goff \& Smith, 2005) and stratified purposeful sampling methods (Patton, 2002) to select the particular subgroups. Although we did not 
utilize triangulation with multiple analysts, the analysis attempted to provide a "thoughtful, systemic triangulation” (Patton, 2002, p. 563) through other methods and the direct use of the CATS Model to guide (but not limit) data analysis.

Phase 2. Utilizing the codebook developed, participant interviews were then divided into subgroups based on the participants' quantitative scores on measures that were administered during the original data collection. The intent of this type of stratified purposeful categorizing was to capture major variations in themes among subgroups of participants based upon their quantitative scores. For the analysis portion of the current study, scores from the following quantitative research instruments were utilized to create sub-groups: the Dyadic Adjustment Scale (DAS; Spanier, 1976) and the Purdue Post-Traumatic Stress Disorder Scale-Revised (PPTSD-R; Lauterbach \& Vrana, 1996).

Dyadic Adjustment Scale (DAS). Relationship satisfaction/functioning was assessed with the DAS (Spanier, 1976), which is a 32-item, variable-Likert measure assessing the quality of the relationship as perceived by both partners. Total scores range from $0-151$, with higher scores indicating greater relationship satisfaction. The DAS has demonstrated good internal consistency on the total score (alpha = .96; Fischer \& Corcoran, 2000). The DAS has adequate convergent validity correlations (.86 - .88) with the Locke-Wallace Marital Adjustment Test (LWMAT, Locke \& Wallace, 1959, as cited in L’Abate \& Bagarozzi, 1993), from which it was derived. Examples of DAS items include the following: How often have you discussed or considered divorce, separation, or terminating your relationship; How often do you and your partner “get on each other's nerves"; and Do you and your partner engage in outside interests together?

Purdue Post-Traumatic Stress Disorder Scale-Revised (PPTSD-R). The PPTSD-R (Lauterbach \& Vrana, 1996) consists of 17 items that correspond to each Diagnostic and Statistical Manual for Mental Disorders, $4^{\text {th }}$ Edition, diagnostic criteria for PTSD (APA, 1994), with three 
subscales that reflect the three general symptom categories of Re-experiencing (4 items), Avoidance (7 items), and Arousal (6 items). The PPTSD-R items are scored from 1 (“Not at all”) to 5 (“Often”), with continuous total scores ranging from 17-85, with higher scores indicating greater PTSD symptoms. The measure, which does not provide a diagnosis or cut-off score, asks participants to indicate how often each reaction occurred during the previous month. The PPTSD-R has been shown to have adequate internal consistency, with coefficient alpha for the total score at .91 and subscale alphas at .84, .79, and .81 for the Re-experiencing, Avoidance, and Arousal subscales, respectively (Lauterbach \& Vrana, 1996). The scale also has demonstrated adequate testretest reliability for the total score (.72) and the subscales (.48 - .71). The PPTSD-R has demonstrated adequate convergent and discriminate validity (Lauterbach \& Vrana, 1996). Examples of items from the PPTSD-R include the following: Have you had upsetting dreams about the event (Re-experiencing subscale); Did you avoid activities or situations that might remind you of the event (Avoidance subscale); and Are you more jumpy or easily startled by noises (Arousal subscale).

One of the unique features of the current study was the use of survey data from both partners to develop subgroups for qualitative data analysis. Based on the quantitative score data, the five couples with the highest mean scores and the five couples with the lowest mean scores on the DAS and PPTSD-R were identified for specific analysis. This was accomplished by pairing all of the participants with their partners to calculate their mean scores (i.e., couple score). Once these scores were determined, the five couples with the highest average scores and the five couples with the lowest average scores on each measure were evaluated and analyzed, providing within couple interview data to analyze and compare. All analyses were conducted using the "couple" as the unit of analysis. For this reason, all of the participants selected to represent a particular group (i.e., high/low trauma symptoms, high/low relationship satisfaction) had scores on the PPTSD-R or DAS 
that were similar to their partners (i.e., both partners either had relatively high scores or relatively low scores on the measures), in order to identify themes from the subgroup participants' qualitative interview data.

The five couples included in the highly satisfied group had mean DAS scores ranging from 129.5 to 149. The five couples in the lowest DAS group had mean scores ranging from 70 to 86.5. The five couples with the lowest trauma symptoms included couples with mean PPTSD-R scores ranging from 17.5 and 23. Finally, the couples included in the high PTSD group had mean PPTSDR scores ranging from 52 to 65.5. Thus, there were four total quadrants or subgroups of participant couples (highest and lowest trauma symptoms, highest and lowest relationship satisfaction).

However, there was overlap between two of the groups, as the high relationship satisfaction and low trauma symptoms subgroups consisted of the same five couples). Thus, the final sample resulted in data from 15 total couples ( $n=30$ participant interviews). While there was some overlap between couples, the four groups were each analyzed independently to identify how these four subgroups described their relationship functioning. For the current study, partners who were similar in their quantitative scores (within couples data) and who "fit" the four quadrants or subgroups based on high and low quantitative scores (the between couples data analysis) were included for the final qualitative data analysis for this study.

\section{Results}

Analysis of the qualitative data resulted in five salient themes: communication, conflict management, roles, support/nurturance, and post-traumatic growth. Within each of the broad themes, multiple sub-themes were also discovered. Communication was delineated into openness of communication, information sharing, and reciprocity. Conflict management included the subthemes of conflict resolution and conflict avoidance. Roles were delineated into perceived role equality and role satisfaction. Sub-themes within support/nurturance included 
empathy/affirmation/effort, deployment contact, and lived experiences. Lastly, post-traumatic growth revealed two sub-themes, including individual and relational post-traumatic growth. The qualitative results are summarized in Figure 1.

As might be expected, data analysis revealed strong commonalities among the highly satisfied couples and those with low levels of trauma symptoms. Significant commonalities also were found among couples with low relationship satisfaction and those with high levels of posttraumatic symptoms (which included different couples in each group). Therefore, as the discussion of the subsequent categories unfolds, each salient sub-category will be discussed within the context of: (a) Group A: highly satisfied couples and couples who reported low trauma symptoms (i.e., the same five couples); and (b) Group B: couples with low marital satisfaction and high trauma symptoms. When there are differences between the Group B couples, these differences will be described by individual group (i.e., low marital satisfaction, high trauma symptoms).

\section{Communication Patterns}

Group A. Couples with the highest relationship satisfaction and lowest posttraumatic stress symptoms consistently reported use of open communication and high information sharing in their relationships. During their interviews, the phrase "we talk about everything” was used to describe their style of communication. These couples tended to rely on their ability to communicate as a means of coping with everyday and deployment-related stressors, as well as a means to connect with one another. Exchanges between spouses were often highly affirming, non-threatening, and purposeful.

In most cases, the degree to which couples were able to communicate openly about deployment and war-related issues mirrored their ability to communicate on other issues. Satisfied couples and those with low trauma symptoms tended to openly share the details of the deployment and traumatic experiences. In this regard, these couples had a propensity to demonstrate high levels 
of mutual respect, reciprocity, emotional transparency, and trust, as well as greater information shared from one partner to the other. Below is an example from a female partner, describing their communication:

We talk about so many things and we talk very freely with each other. I know that he has seen some things that he doesn't want to talk about it, and he’s told [me] that. But when he does want to talk about it, he will...I think he maybe doesn’t want to talk about it. But we have talked about some things, just I know that he’s seen some things that he would rather just not talk about. (33F)

Group B. Most characteristic of the couples with the lowest relationship satisfaction (and highest trauma symptoms) was their tendency to practice predominantly closed communication marked by low levels of information sharing and minimal reciprocity. The amount of communication exchanges between these couples also tended to be lower than the number of exchanges between the satisfied couples, and when exchanges did occur, they were more likely to be negatively tinged. When asked to describe their communication with their partners, participants with low relationship satisfaction/high trauma symptoms tended to reply with "It's closed pretty well all the way around,” "No communication,” "Not very good,” "Poor,” "It sucks,” and "Hard.”

One of the most significant characteristics of the communication styles reported by Group B couples with low relationship satisfaction and high trauma symptoms was the lack of reciprocity. These couples tended to report more one-sided communication efforts, little feedback from their spouses when communication efforts did occur, and more negative responses from their spouses when communication was initiated. For example, when asked to describe communication in her marriage, one spouse replied: "I try to talk about things and he'd rather watch T.V., things like that. So, that's hard. And sometimes I've got to the point where there's no point in bringing it up because he’s not going to listen anyway” (45F). 
For many of the Group B couples, significant difficulties were experienced when attempting to discuss issues related to the deployment and trauma exposure. One soldier commented, "I can’t talk to her about anything. Well, she probably listens well...she listens good but just me telling her something, I just can’t do it” (45M). Another spouse stated:

No communication. He’s had no desire since he’s been home to do anything but for himself, which makes me angry...The communication we have is about the kids and work. That's our communication. (43F)

Couples reporting more post-traumatic stress symptoms seemed to have more difficulty discussing traumatic experiences than couples with low levels of post-traumatic stress symptoms. Although not unanimous, the couples with high levels of post-traumatic stress symptoms reported impairments in their ability to communicate openly about the deployment or other trauma related experiences, to listen empathetically to their partners, and to engage in reciprocal communication. Trauma-focused communication was often limited or absent.

\section{Conflict Management}

Closely related to communication styles is conflict management, which is presumably intertwined with, and perhaps inseparable from, a couple's ability to communicate effectively. This theme was identified separately because of its salience within the interviews. Examination of the participants' interviews revealed two distinct conflict management styles: (a) conflict resolution and (b) conflict avoidance.

Group A. Satisfied couples and those with few trauma symptoms strongly endorsed conflict resolution as their method for coping with challenging issues in their marriages. Conflict tended to be dealt with in a respectful and mindful way with the ultimate goal to resolve the conflict and move forward. Efforts to address conflict were most often marked by open and reciprocal communication, low levels of criticism, higher levels of empathy and understanding, and fewer 
negative exchanges. When asked to describe how they resolve conflicts in their relationships, these participants responded with statements such as, "We just talk about it.” For example, one spouse stated, "We talk about it extensively until it is gone. And it, I mean it’s, we pretty much try to air it out until, to the least common denominator so we don’t have to be confronted with it again” (3F). Group A couples practiced what one soldier described as "mindful communication" (21M), a practice of reciprocal and respectful communication in which proper discernment allows couples to carefully and methodically discuss the issues and to bypass the things that are not relevant.

Group B. The greatest use of conflict avoidance came from couples whose day-to-day communication efforts could be described as ineffective, critical, or even absent. In these couples, the use of avoidance tactics was often employed by both partners. Efforts to address a source of contention were commonly met with criticism, stonewalling, or physical departure by at least one spouse. Resolution was rarely, if ever, reached, resulting in a potential pile-up of unresolved conflict, relationship "scars," and emotional devastation. One soldier described the presence of these behaviors in his marriage by stating:

Usually by dropping the subject and walking away from it. I think too often we [don’t] actually finish an argument. Usually, we just end it and walk away from it and then a couple hours later, it’s forgotten hopefully. (41M)

Unsatisfied couples, and more specifically couples with high trauma symptoms, reported greater variability in their conflict management styles. Although a majority of them reported the use of conflict avoidance, a few participants reported efforts to manage conflict similar to Group A couples.

\section{Roles}

Analysis of the interviews resulted in a clear delineation of sub-categories pertaining to roles: perceived role equality and role satisfaction. Couples who perceived their roles in their 
relationship to be relatively equal were more likely to describe their relationship as a partnership and were subsequently more likely to experience higher levels of satisfaction with their roles. Couples tended to formulate their own classifications of equality and inequality. That is, what may have been perceived as equitable for one couple may not have been perceived as such for another couple. Role satisfaction was often related to the degree to which they felt supported and appreciated in their respective roles. Couples who reported greater perception of role inequality were more likely to be dissatisfied with their roles. Role inequality often occurred when there was a significant imbalance of responsibilities within the relationship in which one partner assumed a considerably greater amount of responsibility than the other.

Group A. Satisfied couples and those with low trauma symptoms were very consistent in their reports of perceived role equality and role satisfaction. These couples described a balance of responsibilities that were viewed as equitable by both partners, which ultimately contributed to their level of satisfaction with those roles. The couples used words and phrases such as "partnership," “50/50," “equal partners,” and “co-partners” to describe their relationships. Group A couples had a clear delineation of roles such that, for example, one spouse may assume the role as spiritual and financial leader, whereas the other spouse assumed the roles of caretaker and manager of the home. Underlying couples' perceptions of role equality were elements of respect and flexibility. Couples tended to respect each other's contributions to the relationship and were more willing to assume flexible roles to accommodate their situational requirements (e.g., deployment, transition time, work, days off). When asked to describe her role in her marriage, one spouse responded:

I used to be like the bossier one. I wanted to be in control more and I've kind of tried to take more of a backseat to my husband and let him be the man. We're equal like when we have to make a big decision. We, he doesn’t belittle my opinion. He counts my opinion as very high. (33F) 
Regardless of how the roles were divided, Group A couples were very satisfied with the division of roles and were aware of and appreciative of the roles that their spouses assumed.

Group B. Couples with low marital satisfaction were similar to couples with high levels of trauma symptoms in that they frequently reported dissatisfaction with their marital roles, which were commonly perceived as being unequal. For these couples, their perceptions of role inequality were based on a number factors including low levels of intimacy and/or closeness, low visibility and/or recognition in the partnership, unwelcome changes in character or attitude as a result of role changes, inability to fill a desired role due to medical complications, and having to unwillingly assume a role. Interestingly, not all Group B couples were dissatisfied with having unequal roles. Several participants reported being very satisfied despite inequitable roles. For spouses, satisfaction came from a sense of empowerment and independence, knowing they could handle the home and children if their husbands were absent. One spouse commented on the unequal roles in her marriage:

I'm very satisfied with it. I mean, I think, I wish he'd take a little bit more initiative. But as towards bringing all that on, I brought it upon myself because it’s what I like to do. I like being able to handle everything myself so. And I know what's going on. I don't have to depend on him to tell me. (27F)

\section{Support and Nurturance}

This category embodies three different sub-themes, including empathy/affirmation/effort, levels of deployment contact, and lived experiences. Participants who demonstrated high levels of empathy, affirmation, and effort were more attentive and aware of their partner's experiences. They were better able to identify with or vicariously experience the thoughts, feelings, and attitudes of their spouses (i.e., shared lived experience). These couples were diligent in their efforts to affirm and encourage one another before, during, and after the deployment and often seized any 
opportunity to do so (i.e., effort). They openly demonstrated compassion and were able to maintain supportive relationships throughout the duration of the deployment.

Group A. Highly satisfied couples and those with low trauma symptoms consistently reported high levels of support and nurturance, characterized by high levels of empathy/affirmation/effort, frequent and positive deployment contact, and shared lived experiences. Group A couples were fervent in their efforts to remain connected to each other throughout the deployment to the degree possible. One of the differences between couples with high and low levels of marital satisfaction was that Group A couples were more "opportunistic" in their efforts to remain connected. Even though they were geographically separated and living two very different lives, they were able to empathize with one another in such a way that each partner remained connected and involved in the life of the other and demonstrated a strong interest in what was occurring in each other's lives:

Just our communication, him sharing everything that he was experiencing and seeing and thinking. As well as listening and asking questions about what I was experiencing, you know, just the interaction, the sharing. (3F)

For the Group A couples, there was a strong sense of mutual support and partnership-a sense that both partners were involved with the deployment experience, not just the soldier. Contact with one another was mutually initiated, eagerly anticipated, and met with enjoyment, relief, and a sense of connection.

Group B. Couples who engaged in low levels of empathy, affirmation, and effort also reported greater relationship dissatisfaction, less frequent and more negative interactions, less effort to reassure and affirm each other, and a stunted ability to identify with or vicariously experience their partner’s thoughts, feelings, and attitudes (i.e., detached experiences). These couples generally reported lower relationship satisfaction and lived predominantly individually focused lives during 
and following the deployment. Alternately, couples with low martial satisfaction most frequently reported low levels of empathy/affirmation/effort, moderate to low deployment contact, and detached lived experiences. Four of the Group B participants reported a near absence of support. When asked how his wife supported him during his deployment, one soldier responded, "Not at all, the whole time. All I got was negative stuff” (43M). Another stated, "Okay, she sent things that I requested, she wrote letters...well, actually most of it's not support, complaining. Well, she took care of our family” (5M). One spouse simply responded, "He didn't" (43F).

What seemed to be absent from the experiences of many of the couples with low relationship satisfaction was the same zealous effort that was unanimously extended by the Group A couples to remain in contact, express support and empathy, and demonstrate a robust interest in the experiences of one another. Noticeably absent from the responses of many of the couples with low relationship satisfaction were reports of regular efforts to console, comfort, and encourage one another during the deployment.

Perhaps most interesting were the mixed findings among couples with high trauma symptoms. These couples reported a blend of high and low levels of empathy/affirmation/effort, frequent to low levels of deployment contact, and a combination of shared and detached experiences. When asked how his wife provided him with emotional support during his deployment, one soldier stated, "She would e-mail me constantly...Even today she does the same thing...That was through the entire deployment, and I still see it now” (44M). However, this finding was not universal, as high levels of empathy/affirmation/effort were not consistent among all of the couples with high trauma symptoms. Other couples who reported high trauma symptoms lacked the ability or willingness to understand the hardships faced by their partners and were primarily detached in their deployment experiences.

\section{Post-Traumatic Growth}


The notion of post-traumatic growth (PTG) has gained salience in the literature over the past few years. It suggests that individuals can experience individual growth, positive changes in relationships, a greater appreciation for life, a sense of personal strength, and heightened spiritual development as a result of traumatic exposure and/or experiences (Tedeschi \& Calhoun, 2004). Commonly, trauma survivors report valuable gains as a result of enduring a traumatic event. Among the participants in this study, two sub-categories of PTG were evident, including individual posttraumatic growth and relational post-traumatic growth.

Participants who endorsed individual PTG were able to identify areas of growth and resilience within themselves that were the result of the deployment, trauma exposure, and/or physical separation from their partners, whereas participants who reported relational PTG cited their deployment experience as a source of relational growth and resilience, evident through a more committed and stronger marriage. For some, the changes that occurred as a result of the deployment and/or trauma experiences were temporary and eventually faded away once the novelty eroded. However, others reported changes that continued to endure for long periods of time.

Group A. Satisfied couples consistently reported high levels of relational post-traumatic growth and cohesion that was enduring in nature. These couples were able to recognize opportunities for growth as a result of their deployment experiences. One soldier described how the deployment and other trauma experiences had most affected his relationship with his wife:

The deployment helped to bond us together better. Helped us to be able to be stronger and to really see what our relationship is made out of, that even in the midst of being away from one another, we can still, still hang in there. (3M)

Several Group A couples used phrases such as, “We’ve always been close, but we’re closer," "A finer appreciation of each other," and "Having that faith in the strength of our communication” to describe areas of relational growth. In each of these cases, the positive changes 
that occurred seemed to be enduring, extending beyond the post-deployment transition period. These couples were able to demonstrate resiliency in the face of adversity and were better able to incorporate "lessons learned" into their marriages that served to promote relationship quality. These couples shared an ability to find the "silver lining," to recognize the potential for growth in lessthan-ideal circumstances and were able to focus their attention on the positive facets of their experience rather than ruminating over the negative ones.

Group B. On the other hand, couples with low relational satisfaction were more consistent in their reports of individual post-traumatic growth. These couples were often unable to identify areas of relational growth or improved relationship cohesion as a result of the deployment. In fact, most partners included in the low relationship satisfaction group indicated no relational posttraumatic growth, instead reporting relationship struggles and tension that emerged as a result of the deployment and trauma experiences. Interestingly, couples with high trauma symptoms were more varied in their reports of post-traumatic growth. Some of these couples reported enduring relational post-traumatic growth, while others only reported individual growth. These couples experienced no improvements in relational cohesion or growth as a result of their deployment experiences. Instead, the extreme separation stunted their ability to remain connected to one another and to grow from their experiences. As described by a spouse:

I hate to say, though we pretty just had to start our relationship all over. Because he was gone for eight months, back for six weeks, gone for six months, back for a month, gone for three months, back for two months, and gone for a year. So we pretty much had to start the relationship all over again. (6F)

\section{Discussion}

The goal of the current study was to understand the experiences of military couples regarding the effects of war-related deployment experiences on couple functioning. More 
specifically, this study utilized the core "couple functioning" variables included in the CATS Model (Nelson Goff \& Smith, 2005) as sensitizing concepts to guide the analysis process (i.e., attachment, satisfaction, stability, adaptability, support/nurturance, power, intimacy, communication, conflict, and roles). Using an interpretive phenomenological perspective, qualitative data analysis was performed to extract key themes from a total sample of 45 military couples. Using quantitative scores from the Dyadic Adjustment Scale (DAS; Spanier, 1976) and the Purdue Post-Traumatic Stress Disorder Scale-Revised (PPTSD-R; Lauterbach \& Vrana, 1996), a subsample of 15 couples was identified to examine differences in themes among couples with high and low levels of marital satisfaction, as well as those with high and low levels of trauma symptoms. Five salient themes were consistently reported by the participating couples in the current study, including communication, conflict management, roles, support/nurturance, and post-traumatic growth (See Table 1 for a summary of the group results).

Highly satisfied couples, as well as those with the lowest presence of post-traumatic stress, were more likely to engage in open communication marked by high levels of information sharing and emotional expression. They were also more likely to engage in behaviors that were conducive to conflict resolution and were highly satisfied in their roles. These couples were most likely to enjoy higher frequencies of deployment contact and were predominantly supportive, nurturing, and empathetic towards their spouses. All of these couples were able to identify relational posttraumatic growth and were apt to share in each other's lived experiences. In short, these couples were equipped with the skills and desire to openly communicate, resolve conflict, share in their roles and responsibilities, offer regular and ongoing support and nurturance, and seize opportunities for growth. The significance of these findings is the consistency with which they were reported, which seems to suggest that there are specific relational factors that are characteristic of wellfunctioning, satisfied, and resilient couples. 
An overall finding was the degree of consistency reported by the couples with high relationship satisfaction and a low presence of post-traumatic stress symptoms. These couples were uniform in their reports of communication and conflict management styles, roles, support and nurturance, and post-traumatic growth. However, this consistency was not replicated by the couples with low relationship satisfaction and high levels of post-traumatic symptoms, as might be expected. These couples tended to be far more variable in their reports of the above mentioned areas. They maintained a propensity toward a certain trend (e.g., closed communication, conflict avoidance, role dissatisfaction); however, some couples in each group provided feedback that was counter to the overall trend (e.g., role satisfaction, high levels of support, conflict resolution).

Underlying each of the major themes were elements of good communication, an indication that a couple's ability to successfully engage in meaningful, supportive, and open communication affects multiple dimensions of the marital relationship. A couple's ability to effectively communicate is critical to their ability to navigate through conflict, to discuss the division of roles, to offer ongoing support and encouragement, and to examine ways in which their relationship has grown or changed. It can be posited that the ability to communicate is the foundation of many other critical relationship dynamics, and the presence or absence of good communication is a determinant of numerous areas of couple functioning, a finding consistently acknowledged in the field.

While it seems clear from the current data that satisfied relationships tend to be predominantly open, reciprocal, equal, and supportive, unsatisfied couples in the current study demonstrated a range of interpersonal dynamics from open to closed communication, both conflict avoidance and conflict resolution, role satisfaction and dissatisfaction, and high and low levels of support. One explanation for this may be that the presence of high levels of trauma symptoms creates challenges within the marital relationship that contribute to low relationship quality, a finding that is consistent with those presented by Nelson Goff et al. (2007) and indicated in the 
CATS Model (Nelson Goff \& Smith, 2005). This may be due to the PTSD symptoms of emotional numbing and hyperarousal (Riggs et al., 1998) and the potential for trauma to cause individuals to be withdrawn, edgy, and preoccupied with themselves and their traumatic experiences, all of which can interfere with their ability to engage in affectionate, mutually supportive relationships and with resuming prewar responsibilities (Solomon, Waysman, Levy, et al., 1992).

Prior research has uncovered a link between the presence of trauma symptoms and marital satisfaction (Nelson Goff et al., 2007; Renshaw et al., 2008; Riggs et al., 1998; Solomon, Waysman, Belkin, et al., 1992). Each of these studies has noted the negative impact of trauma symptoms on the marital relationships. However, as Karney and Crown (2007) have noted, while deployment stress may impact marriage, it may not result in increased divorce rates among military service members. What has yet to be documented is the buffering effect of the marital relationship on the manifestation of trauma symptoms. Can a high functioning, satisfied marriage help mitigate traumatic stress symptoms or, better yet, prevent them from developing altogether?

The Couple Adaptation to Traumatic Stress (CATS) Model (Nelson Goff \& Smith, 2005) proposed ten elements of couple functioning that may be affected when there is a history of trauma in one or both partners, with the notion that individual levels of functioning and any predisposing factors and personal resources directly affect the quality of relational functioning within the couple system. One purpose of the current study was to elucidate areas of couple functioning that are affected when there is a history of deployment and/or war-related trauma, and in doing so, to provide additional empirical support for the couple functioning component of the CATS Model. From the current study, there is clear evidence in support of the elements of communication, conflict, roles, support/nurturance, and satisfaction. However, the current study did not find significant themes involving power, attachment, adaptability, or intimacy. There were irregular accounts by some of the participants that were indicative of adaptability; however, this was not 
supported by the group as a whole. This is not to suggest that these areas are not relevant issues among military couples or those experiencing other types of traumatic events. It does indicate that these themes were not consistently reported among the couples in response to the particular questions asked of them or reported by the selected subgroups of couples in this study.

In addition to identifying specific relational components of the CATS Model (Nelson Goff \& Smith, 2005), an additional contribution from the current study was the inclusion of posttraumatic growth (PTG; Tedeschi \& Calhoun, 2004) into the couple functioning portion of the model and the critical link that communication plays in all areas of couple functioning. As reported by the Group A couples, the experience of post-traumatic growth suggests that resiliency and relational growth are possible, even in difficult situations such as deployment and war. The ability for couples to recognize and embrace opportunities to strengthen their marital relationship implies that such opportunities exist. However, it also appears that such opportunities are "in the eye of the beholder" and are not consistently recognized or embraced by couples with low martial satisfaction or those with higher levels of trauma symptoms. It also appears that individual post-traumatic growth is not always conducive to relational growth. Therefore, it can be concluded that relational post-traumatic growth may be possible only when the perceptions of both partners align. If one partner grows more or counter to the relationship or his/her partner, relational functioning actually may be hindered.

The current study contributes an intimate knowledge of the experiences of military couples who have endured the separation of war deployment. It provides empirical support for the CATS Model (Nelson Goff \& Smith, 2005) by elucidating how couple systems may be affected when trauma has occurred. Furthermore, this study identified key relational and interpersonal dynamics that contribute to adaptation to traumatic stress in the couple dyad, namely those associated with communication, roles, conflict management, support and nurturance, and post- traumatic growth. 
Although this study focused solely on the couple functioning component of the CATS Model (Nelson Goff \& Smith, 2005), it provides useful insight into the potential for the marital relationship to serve as a buffer to the manifestation of trauma symptoms in one or both partners. It is particularly unique in its use of couple-level data. Having data that were inclusive of both partners provided a richness and depth that is unmatched by individual level data.

\section{Limitations and Research Implications}

The current study possesses several limitations and implications for future research. The data collected provides a glimpse of a subgroup of couples at a moment in time, which is helpful in assessing a level of relational functioning based on the specific selection criteria used in the current study (specifically high and low trauma symptoms and relationship satisfaction levels). Further research that addresses other groupings of couples or within couple differences in trauma histories and individual and interpersonal functioning levels is necessary and could provide additional relationship functioning concepts, which were not included in the CATS Model (Nelson Goff \& Smith, 2005) or were concepts eliminated in the current study. Also, a longitudinal design would offer further insight into the effects of deployment experiences on couple functioning over time and throughout the deployment cycle (e.g., pre-deployment, early deployment, mid-deployment, late deployment, reintegration) (Karney \& Crown, 2007). Also, all of the data for the current study was collected prior to multiple military deployments and the 2007 troop surge in which thousands of troops were deployed to provide security to Baghdad and Al Anbar Province; therefore, little is known about the effects of multiple deployments on the marital relationship and how this differs from a single deployment. Furthermore, all of the participants in the current study were selfselected, which may have resulted in a skewed participant pool and subsequently skewed results. In addition, the sample included young couples who were currently married or in a committed relationship, which indicates, overall, a highly satisfied sample of couples. A clinical sample of 
couples may yield stronger results related to symptom severity, as the current results may not be generalizable to individuals experiencing severe trauma symptoms, those experiencing severe dissatisfaction with their relationship, or those who have been married longer and experienced multiple deployments or separations.

It should also be noted that although it was part of the larger study, the spouses’ prior trauma symptoms or the impact of the spouses' trauma history on the soldiers was not directly addressed as part of the current study. Finally, all of the couples included in the current study were couples in which the male partner had active military duty and had been deployed only once. Future research should assess similarities and differences in posttraumatic stress symptoms in female soldiers and how these symptoms are manifested or maintained in the couple relationship.

\section{Clinical Implications}

When viewed as a systemic phenomenon instead of simply an individual one, trauma symptoms can best be treated with the inclusion of the spouse and family members. Although the current research offers less clarity about what typifies unsatisfied couples and those reporting high traumatic stress, because of the variation in results, it does offer insight into the characteristics of highly satisfied and resilient couples (i.e., more consistent findings in Group A couples). Clinicians may integrate the findings from the current study into the therapeutic process to help strengthen marital relationships and encourage resilience by integrating core concepts such as communication, roles and responsibilities, conflict management, and support/nurturance. For example, the current study suggests that open communication envelopes a number of interpersonal dynamics, such as reciprocity, high information sharing, emotional transparency, and conflict resolution. Each of these may be dealt with specifically within the therapeutic process through modeling, experiential exercises, and homework assignments. Couples may be assisted in sharing details of their traumatic experiences and offering affirming and supportive feedback. 
It is clear from the current results that communication is a critical component of successful and satisfying marital relationships, a notion that is quite well-known, but nonetheless deserves restating and emphasizing. Communication underlies nearly every aspect of relational functioning, and therefore its inclusion into the therapeutic process as a central element retains great merit. The current study also emphasizes the importance of achieving a balance in roles and responsibilities within the marital relationship, a task that can be addressed within the therapeutic context. Furthermore, the implications from the current research suggest that maintaining high levels of support and nurturing behaviors is important in enhancing marital satisfaction for couples facing deployment. This involves regular frequent contact between spouses that is markedly and mutually positive and affirming. It also involves the sense of a shared experience, in which both partners respect and empathize with one another. Within the clinical realm, practitioners can assist couples in recognizing the efforts of their partners and in affirming each other, with the ultimate goal of increasing the number of supportive and nurturing behaviors shared between spouses.

As long as military service members continue to be deployed into war zones, marriages will be at the mercy of extended separations and traumatic experiences. However, what is becoming more evident is that these experiences do not have to be the end all for military marriages. In fact, it is possible for the marriages of military couples to be strong, resilient, and to prosper in the face of such adversities. As research continues and more is understood about how to prevent the negative effects on military marriages, encouraging resilience and growth and managing trauma symptoms within the couple relationship, psychoeducational and treatment programs can be tailored to directly address these needs in a proactive and preventative manner.

\section{References}

Allen, E. S., Rhoades, G. K., Stanley, S., M., \& Markman, H. J. (2010). Hitting home: Relationships 
between recent deployment, posttraumatic stress symptoms, and marital functioning for Army couples. Journal of Family Psychology, 24, 280-288. doi: 10.1037/a0019405

Arzi, N.B., Solomon, Z., \& Dekel, R. (2000). Secondary traumatization among wives of PTSD and post-concussion casualties: Distress, caregiver burden, and psychological separation. Brain Injury, 14, 725-736. doi: 10.1080/026990500413759

Cook, J. M., Riggs, D. S., Thompson, R., Coyne, J. C., \& Sheikh, J. I. (2004). Posttraumatic stress disorder and current relationship functioning among World War II ex-prisoners of war. Journal of Family Psychology, 18, 36-45. doi: 10.1037/0893-3200.18.1.36

Dekel, R., \& Monson, C. M. (2010). Military-related post-traumatic stress disorder and family relations: Current knowledge and future directions. Aggression and Violent Behavior, 15, 303-309. doi:10.1016/j.avb.2010.03.001

Di Nola, G. (2008). Stressors afflicting families during military deployment. Military Medicine, 173(5), v-vii.

Dirkzwager, A. J. E., Bramsen, E., Adèr, H., \& van der Ploeg, H. M. (2005). Secondary traumatization in partners and parents of Dutch peacekeeping soldiers. Journal of Family Psychology, 19, 217226. doi: 10.1037/0893-3200.19.2.217

Eaton, K., Hoge, C., Messer, S., Whitt, A., Cabrera, O., McGurk, D., Cox, A., \& Castro, C. (2008). Prevalence of mental health problems, treatment need, and barriers to care among primary careseeking spouses of military service members involved in Iraq and Afghanistan deployments. Military Medicine, 173(11), 1051-1056.

Figley, C.R., (1985). From victim to survivor: Social responsibility in the wake of catastrophe. In C. R. Figley (Ed.), Trauma and its wake: The study and treatment of PTSD (pp. 398-415). New York: Brunner/Mazel.

Fischer, J., \& Corcoran, K. (2000). Measures for clinical practice: A sourcebook: Couples, families, 
and children (3rd ed., Vol. 1). New York: The Free Press.

Karney, B. R., \& Crown, J. S. (2007). Families under stress: An assessment of data, theory, and research on marriage and divorce in the military. Santa Monica, CA: RAND.

L’Abate, L., \& Bagarozzi, D. A. (1993). Sourcebook of marriage and family evaluation. New York: Brunner/Mazel.

Lauterbach, D., \& Vrana, S. (1996). Three studies on the reliability and validity of a self-report measure of posttraumatic stress disorder. Assessment, 3, 17-25. doi: 10.1177/107319119600300102

Mikulincer, M., Florian, V., \& Solomon, Z. (1995). Marital intimacy, family support, and secondary traumatization: A study of wives of veterans with combat stress reaction. Anxiety, Stress, and Coping, 8, 203-213. doi: 10.1080/10615809508249373

Monson, C. M., Taft, C. T., \& Fredman, S. J. (2009). Military-related PTSD and intimate relationships: From description to theory-driven research and intervention development. Clinical Psychology Review, 29, 707-714. doi: 10.1016/j.cpr.2009.09.002

National Center for Post Traumatic Stress Disorder. (2009). Retrieved October 2, 2009 from www.ncptsd.va.gov.

Nelson, B.S., \& Wampler, K. (2000). Systemic effects of trauma in clinic couples: An exploratory study of secondary trauma resulting from childhood abuse. Journal of Marital and Family Therapy, 26(2), 171-184. doi: 10.1111/j.1752-0606.2000.tb00287.x

Nelson Goff, B. S., Crow, J., Reisbig, A., \& Hamilton, S. (2007). The impact of individual trauma symptoms of deployed soldiers on relationship satisfaction. Journal of Family Psychology, 21(3), 344-353. doi: 10.1037/0893-3200.21.3.344

Nelson Goff, B. S., Crow, J. R., Reisbig, A. M. J., \& Hamilton, S. (2009). The impact of soldiers’ deployments to Iraq and Afghanistan: Secondary traumatic stress in female partners. Journal of Couple and Relationship Therapy, 8, 291-305. doi: 10.1080/15332690903246085 
Nelson Goff, B. S., Reisbig, A., Bole, A., Scheer, T., Hayes, E., Archuleta, K., ...Smith, D. B. (2006).

The effects of trauma on intimate relationships: A qualitative study with clinical couples. American Journal of Orthopsychiatry, 76(4), 451-461. doi: 10.1037/0002-9432.76.4.451

Nelson Goff, B. S., \& Smith, D. (2005). Systemic traumatic stress: The Couple Adaptation to Traumatic Stress Model. Journal of Marital and Family Therapy, 31(2), 145-157. doi: 10.1111/j.1752-0606.2005.tb01552.x

Patton, M. Q. (2002). Qualitative research and evaluation methods, $3^{\text {rd }}$ ed. Thousand Oaks, CA: Sage.

Renshaw, K. D., Rodrigues, C. S., \& Jones, D. H. (2008). Psychological symptoms and marital satisfaction in spouses of Operation Iraqi Freedom Veterans: Relationships with spouses' perceptions of veterans' experiences and symptoms. Journal of Family Psychology, 22, 586-594. doi: 10.1037/0893-3200.22.3.586

Renshaw, K. D., Rodrigues, C. S., \& Jones, D. H. (2009). Combat exposure, psychological symptoms, and marital satisfaction in National Guard soldiers who served in Operation Iraqi Freedom from 2005 to 2006. Anxiety, Stress \& Coping, 22, 101-115. doi: 10.1080/10615800802354000

Riggs, D., Byrne, C., Weathers, F., \& Litz, B. (1998). The quality of the intimate relationships of male Vietnam veterans: Problems associated with posttraumatic stress disorder. Journal of Traumatic Stress, 11(1), 87-101. doi: 10.1023/A:1024409200155

Ruger, W., Wilson, S. E., \& Waddoups, S. L. (2002). Warfare and welfare: Military service, combat, and marital dissolution. Armed Forces \& Society, 29, 85-107. doi: 10.1177/0095327X0202900105

Solomon, Z., Waysman, M., Belkin, R., Levy, G., Mikulincer, M., \& Enoch, D. (1992). Marital relations and combat stress reaction: The wives’ perspective. Journal of Marriage and the Family, 54, 316-326.

Solomon, Z., Waysman, M., Levy, G., Fried, B., Mikulincer, M., Benbenishty, R., ... Bleich, A. (1992). From front line to home front: A study of secondary traumatization. Family Process, 31(3), 289- 
302. doi: 10.1111/j.1545-5300.1992.00289.x

Spanier, G. B. (1976). Measuring dyadic adjustment: New scales for assessing the quality of marriage and similar dyads. Journal of Marriage and the Family, 38, 15-28.

Tanielian, T., \& Jaycox, L. (Eds.). (2008). Invisible wounds of war: Cognitive and psychological injuries, their consequences, and services to assist recovery. Santa Monica, CA: RAND.

Tedeschi, R., \& Calhoun, L. (2004). Posttraumatic growth: A new perspective on psychotraumatology. Psychiatric Times, 21(4). Retrieved 7/15/10 http://www.psychiatrictimes.com/p040458.html. Where are the legions? [SPQR] Global deployment of US forces. (2005). Retrieved November 30, 2005, from http://www.globalsecurity.org/military/library/news 

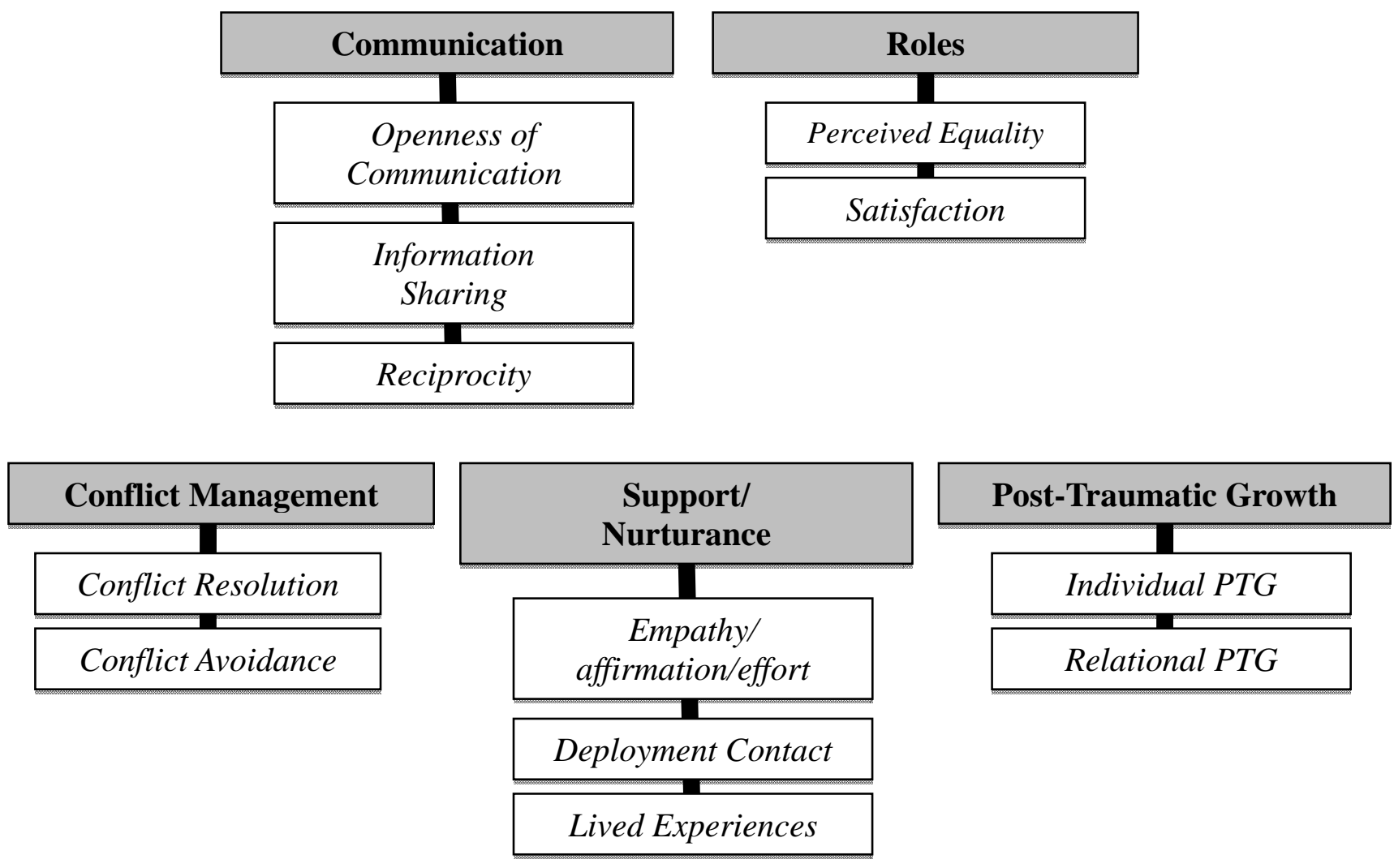

Figure 1: Summary of data analysis themes and sub-themes. 
Table 1

Summary of Results

Group A:

Themes

Communication Styles

Conflict Management

Roles

Support/Nurturance

Post-Traumatic Growth
Consistent findings; open

communication marked by high

levels of information/emotion

sharing, high levels of reciprocity

Consistent findings; conflict

resolution

Consistent findings; perceived

role equality and high levels of

role satisfaction

Consistent findings; high levels

of empathy/affirmation/effort,

high levels of deployment

contact

Consistent findings; high levels

of enduring post-traumatic

growth and improved

relationship cohesion; high levels

of resiliency

\section{Group B:}

Couples with low relationship satisfaction and high levels of post-traumatic symptoms
Consistent findings; closed

communication patterns marked

by restricted information/emotion

sharing, minimal reciprocity

Inconsistent findings;

combination of conflict

resolution and conflict avoidance

Inconsistent findings; variable

reports of role satisfaction/

dissatisfaction and perceived role

equality/inequality

Inconsistent findings; variable

levels of empathy/

affirmation/effort and

deployment contact

Inconsistent findings; variable

reports of individual and

relationship PTG 